\title{
Site-dependent induction of jasmonic acid-associated chemical defenses against western flower thrips in Chrysanthemum
}

\author{
Gang Chen ${ }^{1,2} \cdot$ Hye Kyong Kim ${ }^{1} \cdot$ Peter GL Klinkhamer ${ }^{1} \cdot$ Rocío Escobar-Bravo $^{1}$
}

Received: 11 August 2019 / Accepted: 11 October 2019 / Published online: 27 November 2019

(c) The Author(s) 2019

\begin{abstract}
Main conclusion Local and systemic induction of JA-associated chemical defenses and resistance to western flower thrips in Chrysanthemum are spatially variable and dependent on the site of the JA application.
\end{abstract}

\begin{abstract}
Plants have evolved numerous inducible defense traits to resist or tolerate herbivory, which can be activated locally at the site of the damage, or systemically through the whole plant. Here we investigated how activation of local and systemic chemical responses upon exogenous application of the phytohormone jasmonic acid (JA) varies along the plant canopy in Chrysanthemum, and how these responses correlate with resistance to thrips. Our results showed that JA application reduced thrips damage per plant when applied to all the plant leaves or when locally applied to apical leaves, but not when only basal leaves were locally treated. Local application of JA to apical leaves resulted in a strong reduction in thrips damage in new leaves developed after the JA application. Yet, activation of a JA-associated defensive protein marker, polyphenol oxidase, was only locally induced. Untargeted metabolomic analysis further showed that JA increased the concentrations of sugars, phenylpropanoids, flavonoids and some amino acids in locally induced basal and apical leaves. However, local application of JA to basal leaves marginally affected the metabolomic profiles of systemic non-treated apical leaves, and vice versa. Our results suggest that JA-mediated activation of systemic chemical defense responses is spatially variable and depends on the site of the application of the hormone in Chrysanthemum.
\end{abstract}

Keywords Chrysanthemum · Frankliniella occidentalis · Jasmonic acid · Local and systemic induced defenses · Metabolomics

$\begin{array}{ll}\text { Abbreviations } \\ \text { CV-ANOVA } & \text { ANOVA of the cross-validated residuals } \\ \text { JA } & \text { Jasmonic acid } \\ \text { LSD } & \text { Least significant difference } \\ \text { LV } & \text { Latent variable } \\ \text { PLS-DA } & \text { Partial least squares discriminant analysis } \\ \text { PPO } & \text { Polyphenol oxidase } \\ \text { VIP } & \text { Variable importance for projection }\end{array}$

Electronic supplementary material The online version of this article (https://doi.org/10.1007/s00425-019-03292-2) contains supplementary material, which is available to authorized users.

Gang Chen

g.chen@biology.leidenuniv.nl

1 Research Group Plant Ecology and Phytochemistry, Cluster Plant Science and Natural Products, Institute of Biology, Leiden University, Leiden, The Netherlands

2 College of Forestry, Sichuan Agricultural University, Chengdu, China

\section{Introduction}

Plants defend themselves against herbivory by employing a plethora of physical and chemical arsenals. Chemical defenses can exert repellent, anti-nutritive, and/or toxic effects on herbivores, or attract their natural enemies (Howe and Jander 2008). Physical defenses, such as leaf toughness and trichomes, can also increase plant fitness by negatively affecting herbivore performance and preference. Furthermore, these plant defenses can be classified according to their differential regulation as constitutive or inducible defenses (Agrawal and Karban 1999). Constitutive defenses are defined as morphological or chemical-based defensive traits that are always expressed in the plant, irrespective of herbivore attack (Agrawal 2007). Induced plant defenses, however, can be physical- or chemical-related traits that are initiated or elevated upon herbivory (Agrawal 2007). Plantinducible defense responses to herbivory are mainly modulated by the phytohormones jasmonic acid (JA), salicylic 
acid (SA) and ethylene (Bari and Jones 2009; Smith et al. 2009). In general, chewing and cell-content herbivores, certain phloem feeders and necrotrophic pathogens activate the JA signaling pathway (Walling 2000; Glazebrook 2005; Lazebnik et al. 2014), while the SA pathway is generally activated by biotrophic pathogens and phloem feeders (Walling 2000; De Vos et al. 2005; Glazebrook 2005).

Induction of plant defenses by herbivory can occur locally at the site of attack and systemically in undamaged parts of the plant located at a substantial distance from the challenged area (Pieterse et al. 2014). Although these defense responses have been reported to occur in both local and systemic tissues, they often vary in their magnitude and timing, space and time within and among plant species. This variation can be explained by the genetic background, the development plasticity, transmission of long-distance signals, and the vascular architecture of the plant (Van Dam et al. 2001; Arnold and Schultz 2002; Arimura et al. 2004; Orians 2005; Howe and Jander 2008). For example, glucosinolates, which are important chemical defenses against biotic stresses, are reported to be locally and systemically induced by herbivore feeding in tap and lateral roots of several Brassica species, but not in fine roots (Tsunoda et al. 2018). This has been explained by the capacity of plants to increase the protection of tissues that contribute most to plant fitness, such as primary roots. Importantly, these variations can affect herbivore distribution along the plant canopy, and modulate plant-mediated interactions among different herbivore species (Lee et al. 2017).

The western flower thrips [Frankliniella occidentalis, (Pergande)] is one of the most important insect pests (Steenbergen et al. 2018). Thrips feeding damage on flowers, fruits and plant leaves can reduce growth and yield, and affect product appearance and quality (de Jager et al. 1995a, 1995b). Western flower thrips infestation induces the JA signaling pathway in Arabidopsis (Arabidopsis thaliana) (Abe et al. 2008, 2011), turnip (Brassica rapa) (Abe et al. 2009), and tomato (Solanum lycopersicum) (Li et al. 2002; Escobar-Bravo et al. 2017). Furthermore, activation of JAassociated defenses play a prominent role in plant resistance against this pest (Steenbergen et al. 2018). Knowledge about variation in induced defenses against this insect herbivore is therefore important to develop strategies for plant protection in agri- and horti-cultural systems.

Here we have investigated whether local and systemic chemical defense responses to the exogenous application of JA reduce thrips damage and whether these responses vary along the plant canopy in Chrysanthemum. In addition, we have tested whether a differential JA-mediated induction of local and systemic chemical responses correlates with thrips susceptibility. For this, we have conducted insect bioassays to determine the effects of local and systemic JA application on thrips-associated feeding damage along the plant canopy.
In addition, we have determined the activation of JA signaling upon local or systemic application of JA by analyzing the activity levels of the JA-responsive defensive protein, polyphenol oxidase (PPO) (Constabel and Barbehenn 2008; Bosch et al. 2014). PPO activity is a well-known marker of the induction of JA defenses and it has been amply used to monitor local and systemic JA-associated defense responses (Thaler et al. 1999, 2002; Redman et al. 2001). Finally, we have performed a comprehensive non-targeted metabolomic analysis by Nuclear Magnetic Resonance (NMR) to determine how JA application affects Chrysanthemum chemical defenses upon local or systemic induction. NMR offers many advantages over other analytical techniques, as it requires simple sample preparation and provides the most comprehensive structural information, including stereochemical details (see review by Kim et al. 2011). It thus constitutes the ideal tool for broad-range profiling of abundant metabolites (Obata and Fernie 2012), and as such it has been successfully used by our group to study chemical host-plant resistance to western flower thrips in Chrysanthemum (Leiss et al. 2009b). Our study offers a comprehensive analysis of induced chemical defenses in Chrysanthemum, one of the most important cultivated ornamental crops for which thrips represents one of the most damaging insect pests affecting their production worldwide.

\section{Materials and methods}

\section{Plant material and insects}

Chrysanthemum [Chrysanthemum $\times$ morifolium Ramat. cv. Baltica (Asteraceae)] cuttings were provided by Deliflor Chrysanten (Maasdijk, The Netherlands). The cuttings were individually planted in small plastic trays $(2 \mathrm{~cm} \times 2 \mathrm{~cm})$ filled with potting soil and placed in a climate room provided with $20^{\circ} \mathrm{C}, 70 \% \mathrm{RH}, 113.6 \mu \mathrm{mol} \mathrm{m}^{-2} \mathrm{~s}^{-1}$ of photosynthetically active radiation (PAR) and L16:D8 photoperiod. At 10 days after planting, plants were transplanted to plastic pots $(9 \mathrm{~cm} \times 9 \mathrm{~cm} \times 10 \mathrm{~cm})$ containing the same potting soil.

The western flower thrips (Frankliniella occidentalis) [Pergande] was maintained on Chrysanthemum flowers (cultivar Euro Sunny) in a climate room at $23{ }^{\circ} \mathrm{C}, 60 \% \mathrm{RH}$ and L12:D12 photoperiod.

\section{Experimental design}

A preliminary experiment was carried out to explore the overall effects of jasmonic acid (JA) exogenous application on Chrysanthemum resistance to western flower thrips. For this, mock (2.4\% EtOH) or $3 \mathrm{mM} \mathrm{JA}$ in $2.4 \% \mathrm{EtOH}$ solutions were applied to all the plant leaves or basal leaves only (3-4 from the bottom) of Chrysanthemum plants (cv. 'Baltica'). 
Mock and JA-treated plants were then randomly placed in a climate room at $20{ }^{\circ} \mathrm{C}, 70 \% \mathrm{RH}, 113.6 \mu \mathrm{mol} \mathrm{m} \mathrm{m}^{-2} \mathrm{~s}^{-1} \mathrm{PAR}$ and L16:D8 photoperiod. Seven days after the hormone treatments, plants were subjected to non-choice whole-plant thrips bioassays as described below. Next, to obtain a more complete characterization of the effect of JA on the induction of local and systemic chemical defenses against thrips we carried out as a separate experiment with the following induction treatments (Fig. 1): (1) application of JA or mock solution to all the plant leaves, (2) local application of JA or mock solution to leaves 4 and 5 from the bottom (basal leaves), or (3) local application of JA or mock solution to leaves 9 and 10 from the bottom (apical leaves). Leaves were sprayed with $3 \mathrm{mM}$ of JA (Cayman, Ann Arbor, MI, USA) in $2.4 \%$ aqueous ethanol solution as described in Redman et al. (2001). Control plants were sprayed with $2.4 \%$ aqueous
Fig. 1 Schematic representation of the experimental design. Jasmonic acid (JA) or mock solutions were applied to (1) all leaves, (2) basal leaves (4-5) or (3) apical leaves (9-10) of Chrysanthemum plants at day 0 . Seven days after the hormone treatments, JA- and mock-treated plants $(n=5)$ were sampled for determination of polyphenol oxidase (PPO) activity on leaves 5, 6, 8, 9, 13 and

14 from the bottom. Another set of plants was sampled for NMR analysis on leaves 4-5 and 9-10 from the bottom $(n=5)$. The remaining plants $(n=10$ per treatment) were infested with thrips. Evaluation of thrips feeding damage ('silver damage') was carried out at 7 days after thrips infestation (day 14). The leaves colored in purple were treated with JA or mock solutions on day 0

\section{Mock or JA treatment}

Leaves 1-12

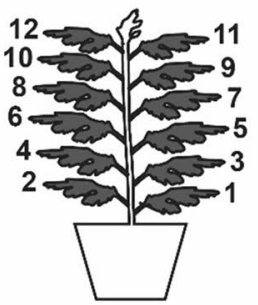

Leaves 4-5

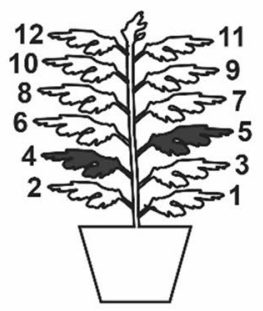

Leaves 9-10

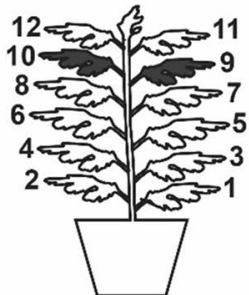

Day 0

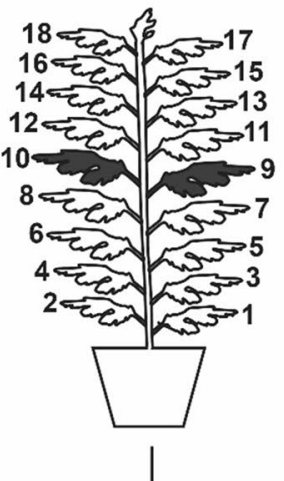

\section{Sampling and thrips infestation}
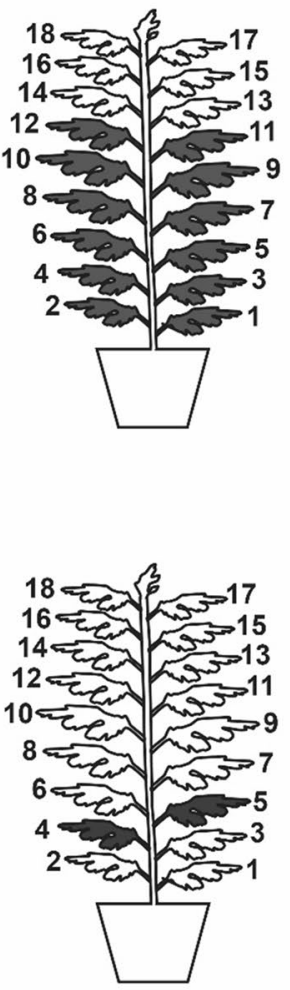

Day 7
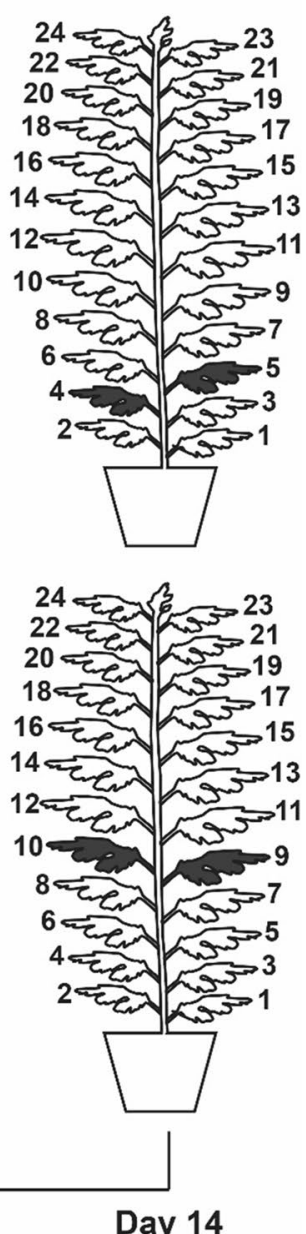

\section{Silver damage}

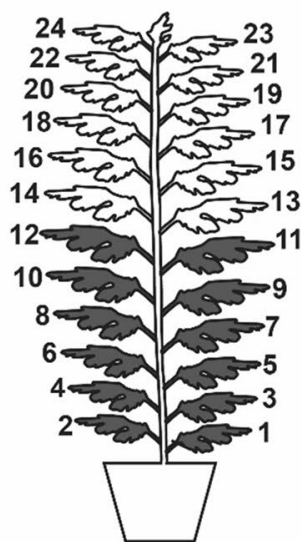


ethanol (mock) solution. Mock- and JA-treated plants were placed in separate climate rooms for $45 \mathrm{~min}$ after the treatment. Thereafter, both control and JA-treated plants were randomly placed in a climate room at $20{ }^{\circ} \mathrm{C}, 70 \% \mathrm{RH}$, $113.6 \mu \mathrm{mol} \mathrm{m}^{-2} \mathrm{~s}^{-1}$ of PAR and L16:D8 photoperiod. At 7 days after JA or mock solutions application, basal (4-5) and apical (9-10) leaves of 5 plants per treatment were sampled for metabolomics analyses by NMR, and leaves 5, 6 , $8,9,13$ and 14 of 5 plants of each treatment were sampled for polyphenol oxidase (PPO) activity. The remaining plants were subjected to non-choice whole-plant thrips bioassays (see below).

\section{Non-choice whole-plant thrips bioassay}

Plants were individually placed into thrips-proof cages as described in Leiss et al. (2009a) ( $n=10$ for each treatment). Ten adult thrips ( 8 females and 2 males) were added to each plant. All cages were randomly placed in a climate room provided with $113.6 \mu \mathrm{mol}$ photons $\mathrm{m}^{-2} \mathrm{~s}^{-1}$ of PAR, $16 \mathrm{~L}: 8 \mathrm{D}$ of photoperiod, $25{ }^{\circ} \mathrm{C}$ and $70 \%$ RH. Seven days after thrips infestation, thrips-associated feeding damage (hereafter referred as 'silver damage') was evaluated in all the leaves of the plant and expressed as the damaged area in $\mathrm{mm}^{2}$ per plant or the silver damage caused by thrips in four groups of leaves: i.e., leaf 1-6, leaf 7-12, leaf 13-18 and leaf 19-24 from the bottom.

\section{Determination of polyphenol oxidase activity}

Polyphenol oxidase (PPO) activity was determined following the methodology described in Stout et al. (1998). Briefly, $0.150 \mathrm{~g}$ of leaf tissue was flash-frozen in liquid nitrogen, ground in a tissue lyser (Qiagen, Hilden, Germany), and homogenized in a $2 \mathrm{ml}$ tube with $1.25 \mathrm{ml}$ ice-cold $0.1 \mathrm{M}$ $\mathrm{pH} 7.0$ phosphate buffer containing $7 \%$ polyvinyl-polypyrrolidone and $0.4 \mathrm{ml}$ of $10 \%$ Triton X-100. The homogenate was vortexed for $2 \mathrm{~min}$ and centrifuged for $10 \mathrm{~min}$ at $11,000 \mathrm{~g}$ at $4{ }^{\circ} \mathrm{C}$. Five microliters of the extract were added to $1 \mathrm{ml}$ of $2.92 \mathrm{mM}$ chlorogenic acid solution in $\mathrm{pH} 8.0$ potassium phosphate buffer. The optical density (OD) at $470 \mathrm{~nm}$ was recorded in a spectrophotometer (UV-1800, Shimadzu, Kyoto, Japan) every $10 \mathrm{~s}$ for one minute. PPO activity was calculated as the increment of OD values per min per gram of fresh weight.

\section{Nuclear magnetic resonance (NMR) analysis}

NMR analysis was performed on basal (leaves 4 and 5) and apical (leaves 9 and 10) leaves at 7 days after the hormone or mock treatments $(n=5)$. Leaves 4 and 5, and 9 and 10, were pooled prior to analysis. Plant material was freeze-dried and ground using a tissue lyser (Qiagen, Hilden, Germany).
Twenty milligrams of fine powder was extracted with $1.5 \mathrm{ml}$ of $80 \%$ methanol- $d 4$ in $\mathrm{KH}_{2} \mathrm{PO}_{4}$ buffer $(90 \mathrm{mM}, \mathrm{pH}=6.0)$ containing $0.02 \%(\mathrm{w} / \mathrm{v})$ trimethyl silyl-3-propionic acid sodium salt- $d 4$ (TMSP). Plant extracts were vortexed for $1 \mathrm{~min}$, ultra-sonicated for $15 \mathrm{~min}$ and centrifuged at $18,890 \mathrm{~g}$ for $15 \mathrm{~min}$ at room temperature. Eight hundred microliters of the supernatant were transferred to the NMR tubes for analysis. The ${ }^{1} \mathrm{H}$ NMR spectra were acquired using a $600 \mathrm{MHz}$ AV-600 spectrometer (Bruker, Billerica, MA, USA) equipped with cryoprobe operating at a proton NMR frequency of $600 \mathrm{MHz}$ at $25{ }^{\circ} \mathrm{C}$, as described in LópezGresa et al. (2012). Deuterated methanol served as internal lock. ${ }^{1} \mathrm{H}$ NMR spectrum consisted of 128 scans requiring $10 \mathrm{~min}$ acquisition time with a digital resolution of $0.25 \mathrm{~Hz} /$ point, a pulse angle of $30^{\circ}(10.8 \mu \mathrm{s})$, and a recycle delay of $1.5 \mathrm{~s}$ per scan. A pre-saturation sequence was used to suppress the residual water signal with low power-selective irradiation at the $\mathrm{H}_{2} \mathrm{O}$ frequency during the recycle delay. Spectra were Fourier-transformed with a $0.3 \mathrm{~Hz}$ line broadening and zero-filled to $32 \mathrm{~K}$ points. Phase and baseline correction of the resulting spectra were done manually, followed by a calibration to TMSP at $0.00 \mathrm{ppm}$ using Topspin (version 2.1, Bruker). ${ }^{1} \mathrm{H}$ NMR spectra was then converted and saved as ASCII files using AMIX (v. 3.7, Bruker). Spectral intensities were scaled to the intensity of the internal standard TMSP and reduced to integrated regions, referred to as buckets, of equal width (0.04 ppm) corresponding to the region of $\delta 10.0-0.2$. The regions in the range of $\delta$ $5.0-4.7$ and $\delta 3.34-3.28$, corresponding to water and methanol, respectively, were removed prior to statistical analyses. Identification of metabolites was based on previous analysis of one- and two-dimensional NMR experiments (COSY, J-resolved, HSQC, HMBC), together with the comparison of reference compounds and previously reported data (van Geest et al. 2016).

\section{Statistical analysis}

Statistical analyses were performed using the SPSS software package (version 23; SPSS Inc., Chicago, IL, USA). Normality and homogeneity of the residuals were first checked using Kolmogorov-Smirnov and Levene's tests, respectively. Differences in silver damage symptoms per plant between JAand mock-treated plants were analyzed by Student's $t$ tests. Effects of the main factors JA and groups of leaves based on their position in the plant (1-6, 7-12,13-18 and 19-24 from the bottom) and their interaction on silver damage symptoms were analyzed by Generalized Linear Models (GLMs) using linear distribution and identity link function. Differences in PPO activity among leaves 5, 6, 8, 9, 13 and 14 detected in JA and mock-treated plants were analyzed by GLMs using linear distribution and identity link function. Data on silver damage and PPO activity determined in plants receiving 
local application or systemic JA application were Log-transformed prior to analysis. Effects of JA, leaf position (4-5 and 9-10) and their interaction on levels of metabolites identified in the NMR analysis were analyzed by GLMs using linear distribution and identity link function. Differences among groups were tested by Fisher's least significant difference (LSD) post hoc test. Patterns of chemical shifts detected by NMR in leaves 4-5 and 9-10 of mock- and JA-treated plants were analyzed by Partial Least Squares Discriminant analysis (PLS-DA) using the SIMCA-P 15 software package (Umetrics, Umeå, Sweden). This analysis determines the variation in $\mathrm{X}$ variables (chemical shifts) modeled by the Y explanatory variable, i.e., mock and JA solution application on basal (leaves 4 and 5), apical (leaves 9 and 10) or on all leaves. The final model was selected according to the minimum number of latent variables showing the highest predicted variation in $\mathrm{Y}\left(Q^{2}\right)$. The chemical shifts with a variable importance for projection (VIP) $>1$ were selected as the important $\mathrm{X}$ variables. Detailed statistical results are shown in Table $\mathrm{S} 1, \mathrm{~S} 2$ and $\mathrm{S} 3$.

\section{Results}

\section{Systemic or local application of JA to apical leaves, but not local application to basal leaves, reduces silver damage per plant}

In a preliminary experiment, our results showed that exogenous application of JA enhanced Chrysanthemum resistance to western flower thrips (Fig. S1a; student $t$ test, $P<0.05)$, but not when JA was locally applied to basal leaves (Fig. S1b; student $t$ test, $P>0.05$ ), suggesting possible constraints in the induction of systemic defenses against this pest. To further investigate this phenomenon, we next determined how JA application to different parts of the Chrysanthemum plant affected thrips resistance in detail. Application of JA to all the leaves of Chrysanthemum plants significantly reduced silver damage symptoms per plant (Fig. 2a, Table S1; student $t$ test, $P<0.05$ ). This reduction was statistically significant for leaves $1-6,7-12$, and 13-18 (Fig. 2b). Local application of JA to basal leaves (4-5) did not significantly reduce the silver damage per plant (Fig. 2c; student $t$ test, $P=0.592$ ), although there was a significant reduction in leaves 13-18 compared to their controls (Fig. 2d). Local application of JA on apical leaves (9-10) significantly reduced the silver damage symptoms per plant (Fig. 2e; Student's $t$ test, $P=0.038$ ). This reduction was significant for leaves 13-18 and, although not significant, also evident for leaves 7-12 (Fig. 2f). Overall, silver damage symptoms were higher in leaves 7-12 and 13-18 compared to leaves 1-6 and 19-24 (Fig. 2b, d, f).

\section{JA induces polyphenol oxidase activity in local but not in systemic leaves}

When JA was applied to all the leaves of Chrysanthemum plants, PPO activity was significantly induced in leaves 5 , 6, 8, 9 and 13, but not in leaf 14, at 7 days after the JA treatment (Fig. 3a, Table S1). Application of JA to basal leaves (4-5) significantly increased PPO activity in leaf 5, while in the other leaves there was a very small and non-significant increase (Fig. 3b). Likewise, application of JA to the apical leaves (9-10) induced PPO locally, i.e., on leaf 9, but not in non-treated leaves (Fig. 3c). Notably, PPO activity levels were higher in the youngest leaves (13 and 14) in both mockand JA-treated plants.

\section{JA effects on the leaf metabolome are local but not systemic}

\section{All leaves treated with JA}

A total of 246 signals were detected in the ${ }^{1} \mathrm{H}$ NMR analysis of leaves corresponding to mock- and JA-treated Chrysanthemum plants. PLS-DA analysis of the metabolomics profiles of basal (4-5) and apical (9-10) leaves of plants from which all the leaves were treated with JA or mock solutions resulted in a model with five latent variables (LVs). This model explained $75.5 \%$ of the total metabolomics variation and $95.5 \%$ of the treatment variation, with a $77.3 \%$ total model predictability (model statistics: $R^{2} X=0.755, R^{2} Y=0.951$ and $Q^{2}=0.773$; CV-ANOVA, $P<0.001$ ) (Fig. 4a). The first LV separated JAtreated basal leaves (4-5) from JA-treated apical leaves (9-10) and mock-treated basal and apical leaves, explaining $40.1 \%$ of the metabolomic variation. The second LV explained $15.8 \%$ and separated basal leaves (4-5) from apical leaves (9-10) of both treatments. Differences among treatments were mainly explained by 101 signals with variable importance for projection (VIP) scores higher than 1 (Figs. $4 \mathrm{~b}$ and S1). Among these, fourteen signals were identified corresponding to sugars (fructose, glucose and sucrose), amino acids (valine, threonine, alanine, arginine, glutamine, asparagine, adenine), organic acids (citric acid), phenylpropanoids (chlorogenic acid, 3,5-dicaffeoylquinic acid) and flavonoids (luteolin-7- $O$ glucoside). JA application significantly increased the levels of sucrose, glucose, threonine, asparagine, phenyl propanoids (chlorogenic acid and 3,5-dicaffeoylquinic acid), the flavonoid luteolin-7-O-glucoside and camphor, and it reduced the levels of citric acid in basal leaves (4-5) at 7 days after the hormone treatment (Fig. 4c, Tables S2 and S3). Overall JA application affected the metabolomic profile of apical (9-10) leaves less strongly than those of basal leaves, but a significant reduction in the leaf content of some amino acids (alanine and glutamine) and a significant induction of adenine, and phenylpropanoids (chlorogenic acid and 3,5-dicaffeoylquinic acid) were 

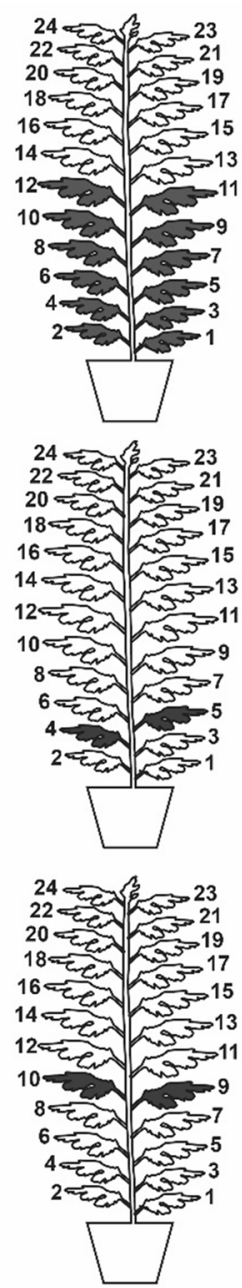

(e)

(a)

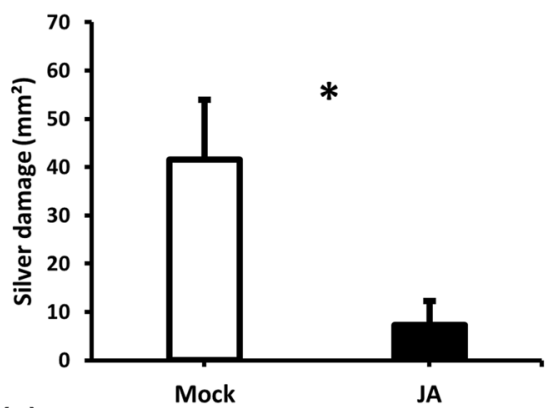

(c)
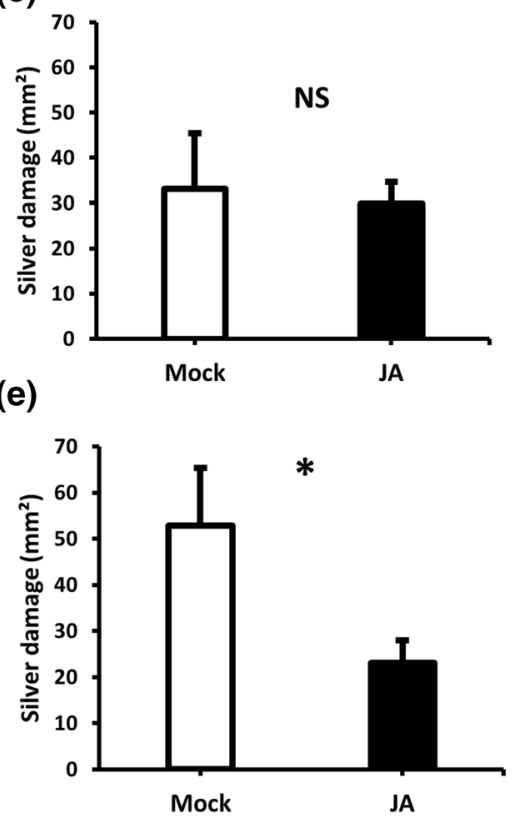

(b)

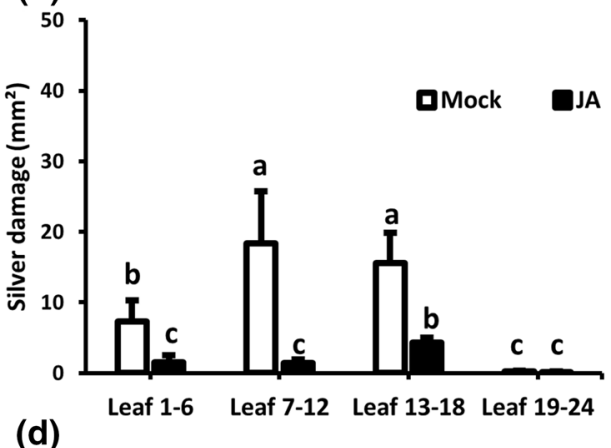

(d)

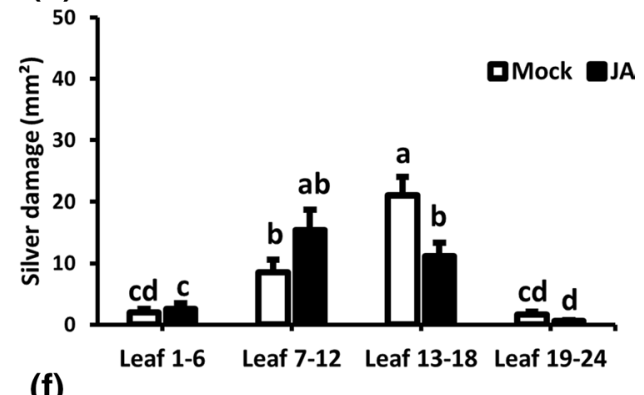

(f)

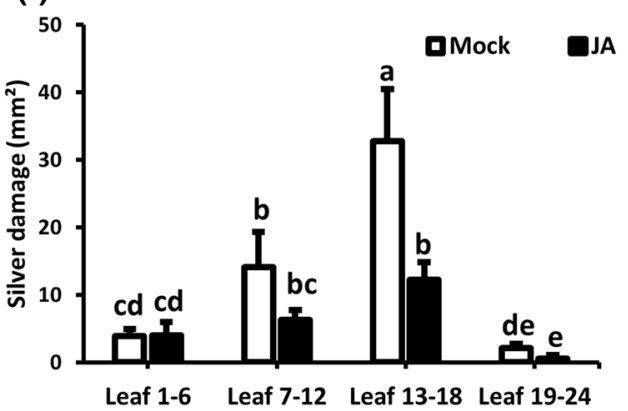

Fig. 2 Effect of systemic and local JA treatment on Chrysanthemum resistance to thrips. Silver damage symptoms (mean \pm SE, $n=10$ ) were determined for the whole plant or separately in four groups of leaves along the plant canopy in mock- and jasmonic acid (JA)treated plants at 7 days after thrips infestation. Mock or JA solutions were applied to all the plant leaves (a and $\mathbf{b}$ ), basal leaves (4-5 from

observed (Fig. 4c, Table S2 and S3). Apical leaves (9-10) showed lower levels of sugars (fructose and sucrose) and phenylpropanoids (chlorogenic acid and 3,5-dicaffeoylquinic acid), and higher levels of amino acids (valine, threonine, alanine, arginine, and adenine) than basal (4-5) leaves, independent of the treatment.

\section{Basal leaves treated with JA}

When plants were treated locally with JA on basal leaves (4-5), the metabolomic responses to the hormone treatment were only evident in those local leaves, while barely altering the chemistry of systemic apical leaves (9-10) (Fig. 5a). The PLS-DA analysis resulted in a model with three LVs explaining $63.1 \%$ of the total metabolomic variation and the bottom; $\mathbf{c}$ and $\mathbf{d}$ ) or to apical leaves (9-10 from the bottom; e and f). Asterisks denote significant differences determined by unpaired $t$ test at $P \leq 0.05$. Different letters indicate significant differences among groups compared by Fisher's LSD test at $P \leq 0.05$; n.s., not significant

$80.9 \%$ of the treatment response, with a $49.4 \%$ total model predictability $\left(R^{2} X=0.631, R^{2} Y=0.809\right.$ and $Q^{2}=0.494$; CVANOVA, $P=0.025)$. The first LV explained $42.7 \%$ of the variance and separated JA-treated basal leaves (4-5) from apical leaves (9-10) of mock- and JA-treated plants. The second LV explained $14.8 \%$ of the variance and separated mock-treated basal leaves (4-5) from the other leaves. These differences were mainly explained by 125 signals with VIP scores higher than 1 (Figs. 5b and S2). JA application to basal leaves (4-5) reduced the levels of sugars (fructose, glucose and sucrose) and the amino acid glutamine, while increasing the levels of the amino acid arginine, phenolic acids and flavonoids in these leaves (Fig. 5c, Tables S2 and S3). No significant differences in the levels of these compounds were observed for the apical leaves (9-10), except 
Fig. 3 Effect of systemic and local JA induction on polyphenol oxidase (PPO) activity in Chrysanthemum. PPO activity (mean $\pm \mathrm{SE}, n=5$ ) was determined on leaves $5,6,8$, 9,13 and 14 from the bottom of mock- and jasmonic acid (JA)-treated plants. Mock or JA solutions were applied to all plant leaves (a), basal leaves

(b) or apical leaves (c). Plants were sampled at 7 days after the hormone treatments. Different letters indicate significant differences among groups compared by Fisher's LSD test at $P \leq 0.05$

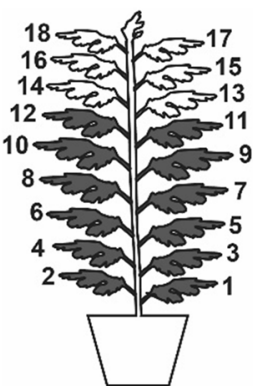

(a)

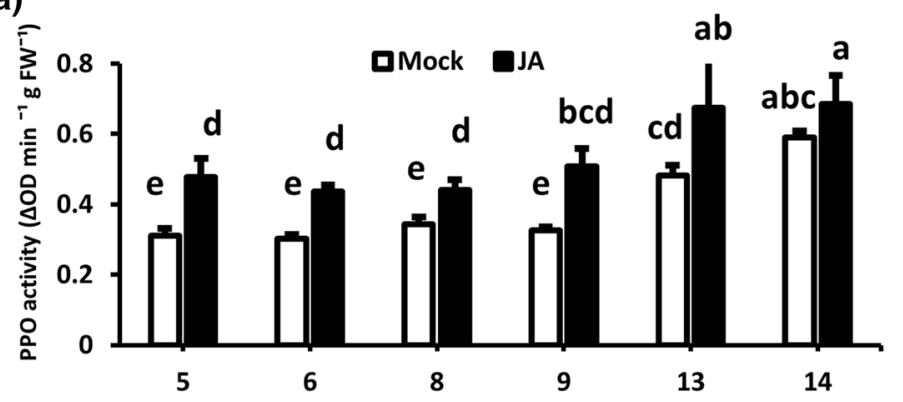

(b)
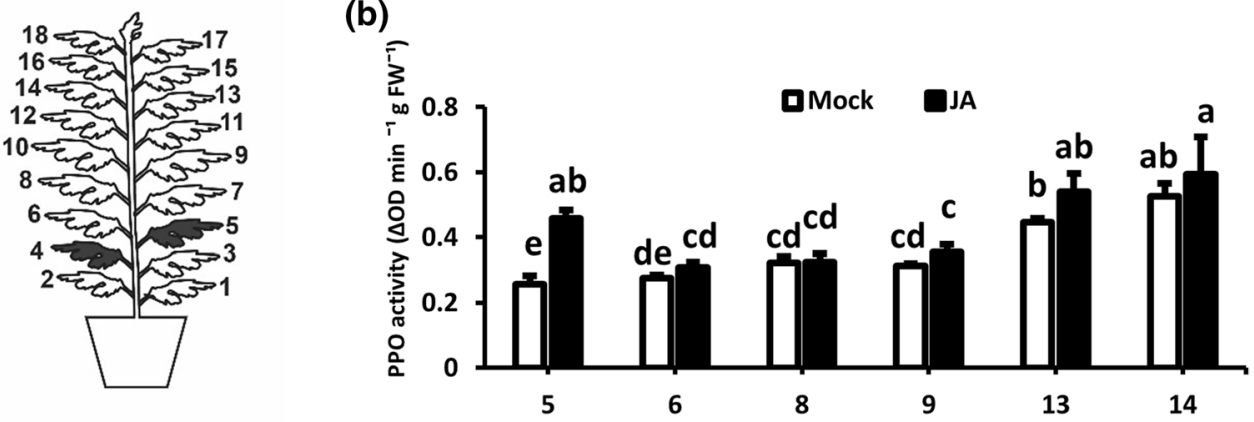

(c)
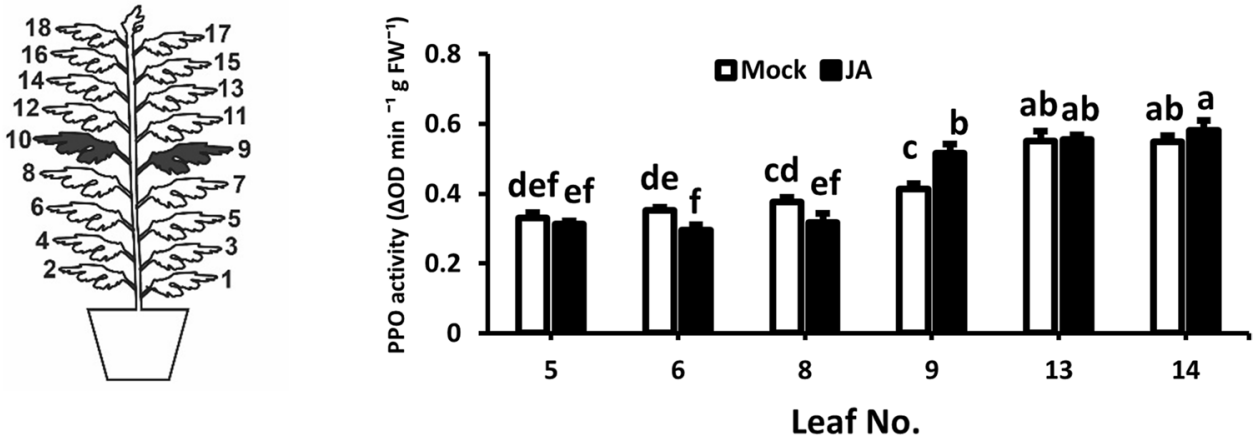

treatments were explained by 100 signals with VIP scores higher than 1 (Figs. 6b and S3). JA significantly reduced the levels of fructose, glutamine and citric acid, and it increased the levels of glucose, adenine, phenylpropanoids (chlorogenic acid and 3,5-dicaffeoylquinic acid) and the flavonoid luteolin-7-O-glucoside in apical leaves (9-10). Notably, although the local application of JA to apical leaves barely affected the overall metabolomic profiles of basal leaves, significant lower levels of sugars (fructose and sucrose), some amino acids (valine, alanine, and glutamine), camphor and myoinositol were observed (Fig. 6c, Table S2 and S3). Levels of sugars (fructose, glucose and sucrose), phenylpropanoids (chlorogenic acid 3,5-dicaffeoylquinic acid), the flavonoid luteolin-7-O-glucoside and some amino acids (glutamine) were significantly lower in mock-treated apical leaves when compared to mock-treated basal leaves, while levels of some amino acids (threonine, alanine and arginine) were significantly higher (Table S2 and S3). 
(a) Score plot of all leaves treated with JA

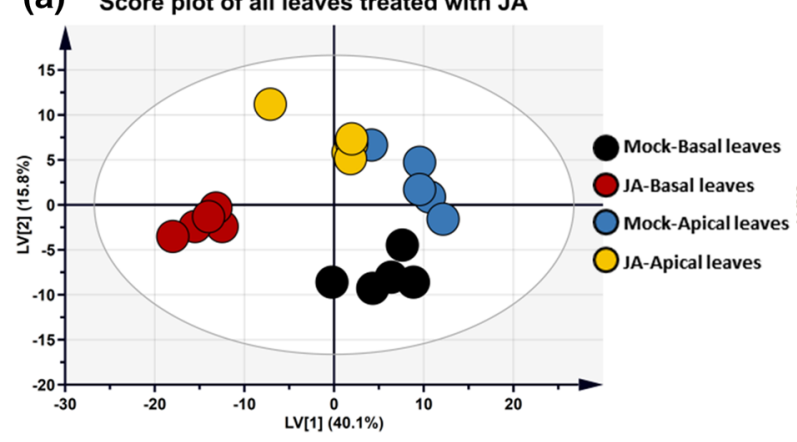

(b) Loading plot of all leaves treated with JA

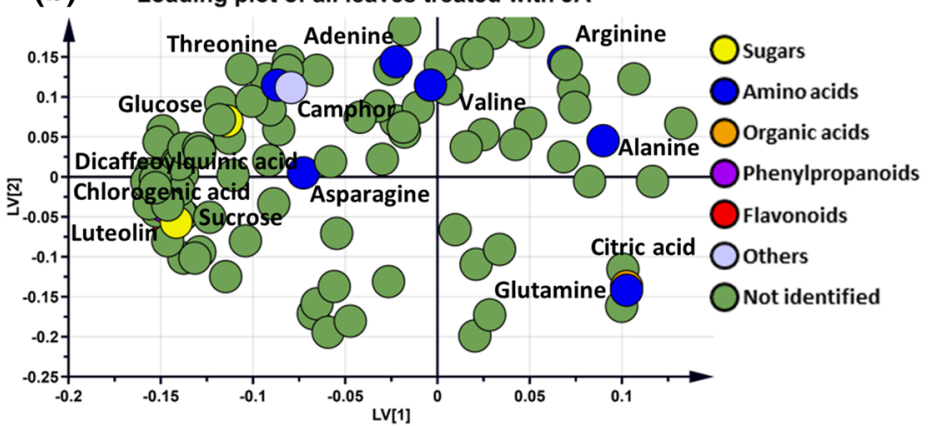

(c) Sucrose

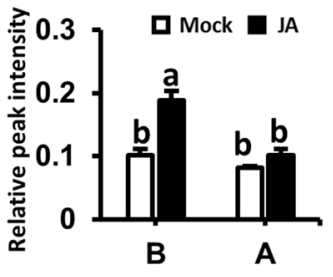

Arginine

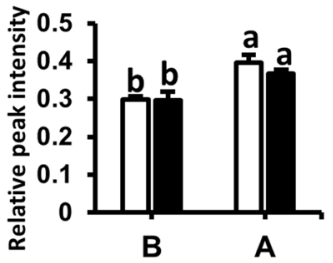

Chlorogenic acid

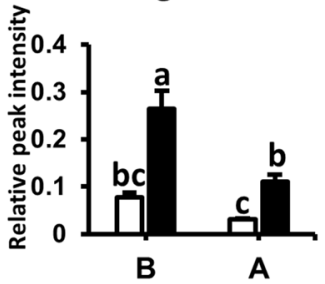

Glucose

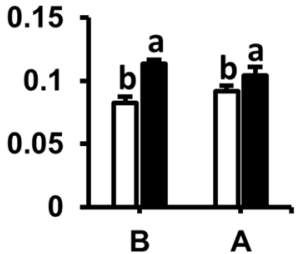

Alanine

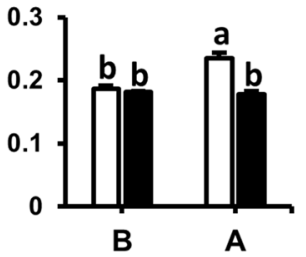

Dicaffeoylquinic acid

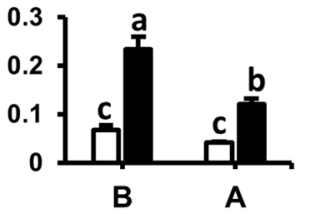

Glutamine

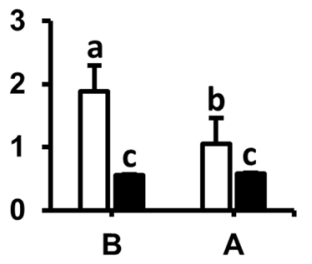

Threonine

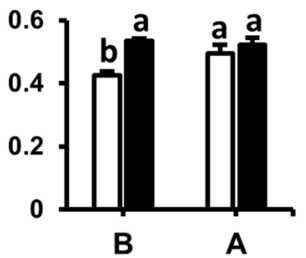

Luteolin-7-Oglucoside

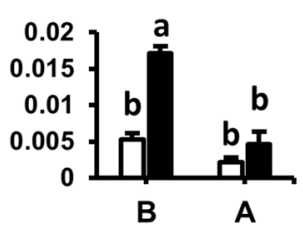

Adenine

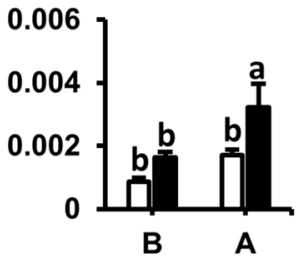

Valine

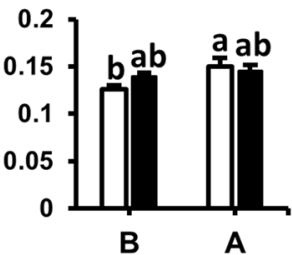

Camphor

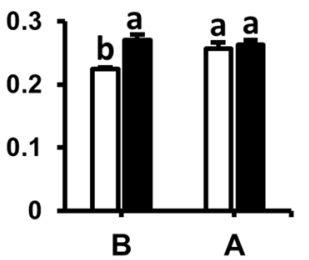

Asparagine

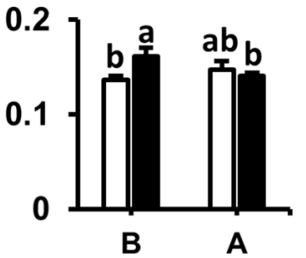

Citric acid

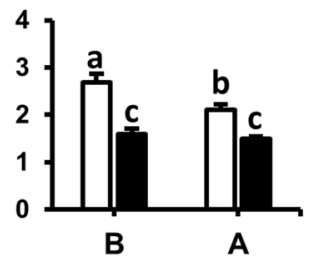

Fig. 4 Metabolic responses of basal and apical Chrysanthemum leaves to systemic application of JA to all the plant leaves. Leaf metabolites were analyzed by NMR in basal (leaf 4-5) and apical (leaf 9-10) leaves of Chrysanthemum plants at 7 days after the application of mock or jasmonic acid (JA) solutions to all plant leaves. Partial least square-discriminant analysis (PLS-DA) was performed on the obtained ${ }^{1} \mathrm{H}$ NMR spectra $(n=5)$. a Score plot showing the first two latent variables (LVs). The ellipse represents the Hotelling
T2 with 95\% confidence. b Loading plot showing important chemical shifts that contribute most to the model (variable importance in projection, VIP $>1$ ). The identified compounds are shown in the plot. (c) Relative peak intensity (mean $\pm \mathrm{SE}, n=5$ ) of the identified compounds in basal (b) and apical (a) leaves of mock- and JA-treated plants is shown. Different letters indicate significant differences among groups compared by Fisher's LSD test at $P \leq 0.05$

western flower thrips Frankliniella occidentalis. Variation in the systemic induction of chemical defenses was not explained by the vertical alignment of local and systemic leaves, and thus their direct vascular connections, nor differences in the local responses to the hormone treatment between apical and basal leaves. On the contrary, levels of constitutive and inducible chemical defenses were higher in basal leaves. 

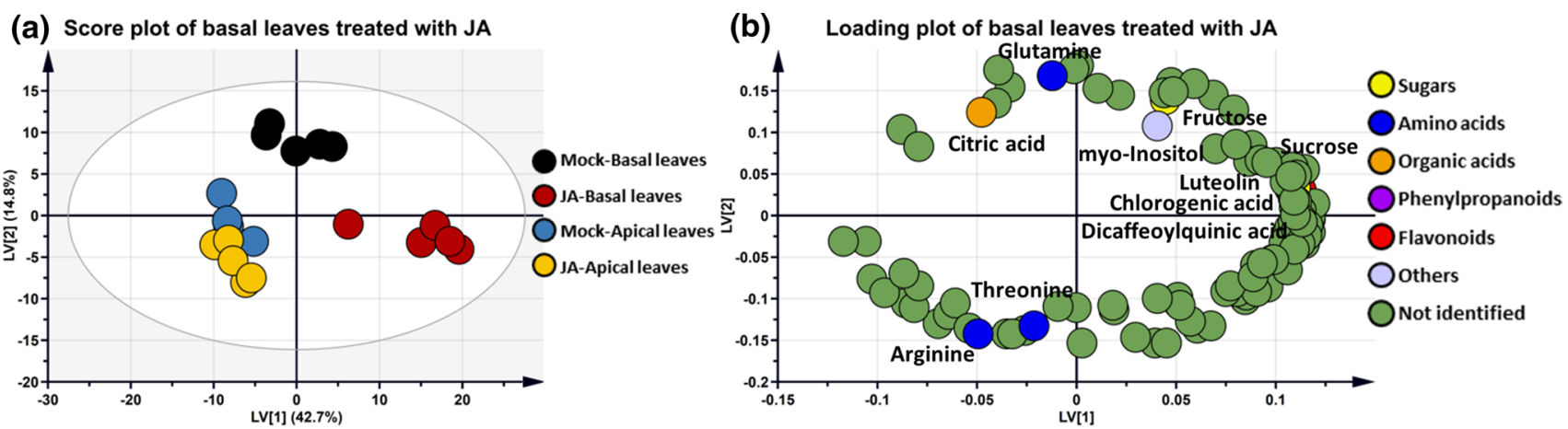

(c)

Fructose

Sucrose

Glutamine

Threonine

Arginine
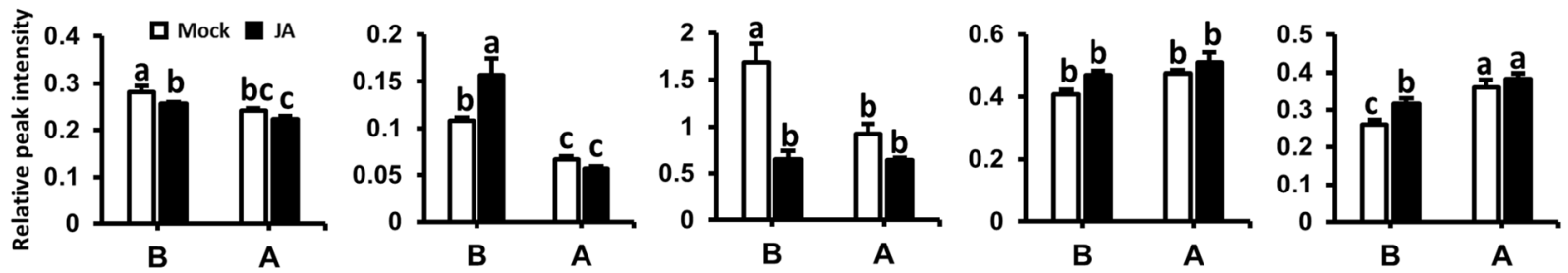

Citric acid

Chlorogenic acid

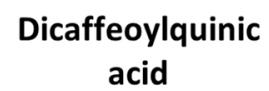

Luteolin-7-O-
glucoside

myo-Inositol
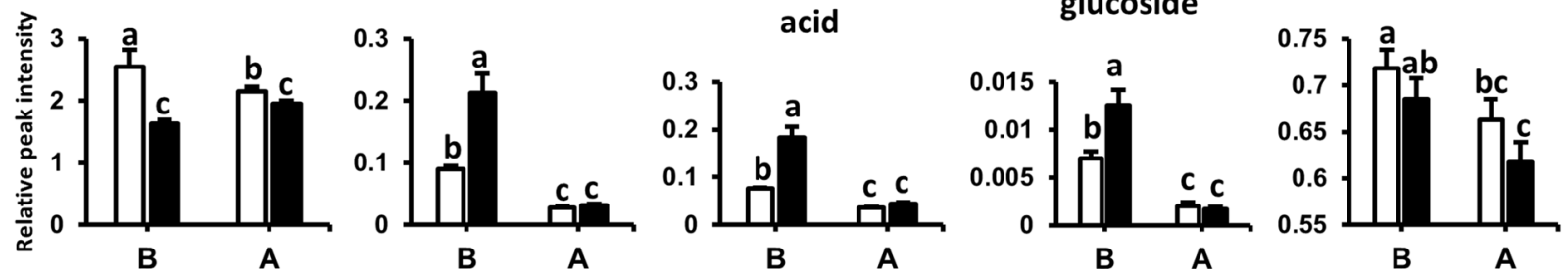

Fig. 5 Metabolomic responses of basal and apical Chrysanthemum leaves to local application of JA to basal leaves. Leaf metabolites were analyzed by NMR in basal (leaf 4-5) and apical (leaf 9-10) leaves of Chrysanthemum plants at 7 days after the local application of mock or jasmonic acid (JA) solutions to basal leaves (4-5 from the bottom). Partial least square-discriminant analysis (PLS-DA) was performed on the obtained ${ }^{1} \mathrm{H}$ NMR spectra $(n=5)$. a Score plot showing the first two latent variables (LVs). The ellipse represents the

Exogenous application of JA has been previously reported to increase plant resistance to thrips in Arabidopsis (A. thaliana) (Abe et al. 2008), cabbage (Brassica oleracea) (Abe et al. 2009) and tomato (S. lycopersicum) (Escobar-Bravo et al. 2017). Here we showed that systemic application of JA also reduced thrips-associated damage in Chrysanthemum. We further demonstrated that local application of JA to basal leaves (4-5) did not affect thrips resistance in systemic apical leaves (7-12), and it slightly reduced silver damage in leaves 13-18 only. Conversely, local JA induction of apical leaves (9-10) strongly reduced thrips damage in these and the adjacent leaves developed after the induction (13-18), which contributed most to the overall reduction in silver damage per plant (Fig. 2e, f). Systemic induction of defenses against pathogens and herbivores has been amply studied in different plant species (Hilleary and Gilroy 2018).
Hotelling T2 with 95\% confidence. b Loading plot showing important chemical shifts that contribute most to the model (variable importance in projection, VIP $>1$ ). The identified compounds are shown in the plot. c Relative peak intensity (mean $\pm \mathrm{SE}, n=5$ ) of the identified compounds in basal (B) or apical (A) leaves of mock- and JA-treated plants is shown. Different letters indicate significant differences among groups compared by Fisher's LSD test at $P \leq 0.05$

Cohen et al. (1993) showed that local application of JA to basal tomato leaves triggered systemic resistance to a fungal pathogen. We hypothesized that diminished systemic induction of resistance to thrips when JA is locally applied to basal leaves might be explained by a reduced capacity of these leaves to respond to the hormone treatment. For instance, a reduced inducibility upon herbivory or application of JA in old leaf tissues has been observed in other plant species (Constabel et al. 2000; Ohnmeiss and Baldwin 2000; van Dam et al. 2001; Köhler et al. 2015; Chen et al. 2018). Furthermore, Van Dam et al. (2001) reported that simulated damage in old leaves did not trigger a strong systemic response when compared to young leaves in wild tobacco (Nicotiana attenuata). The underlying mechanisms of these differential induction patterns, however, remain elusive. 

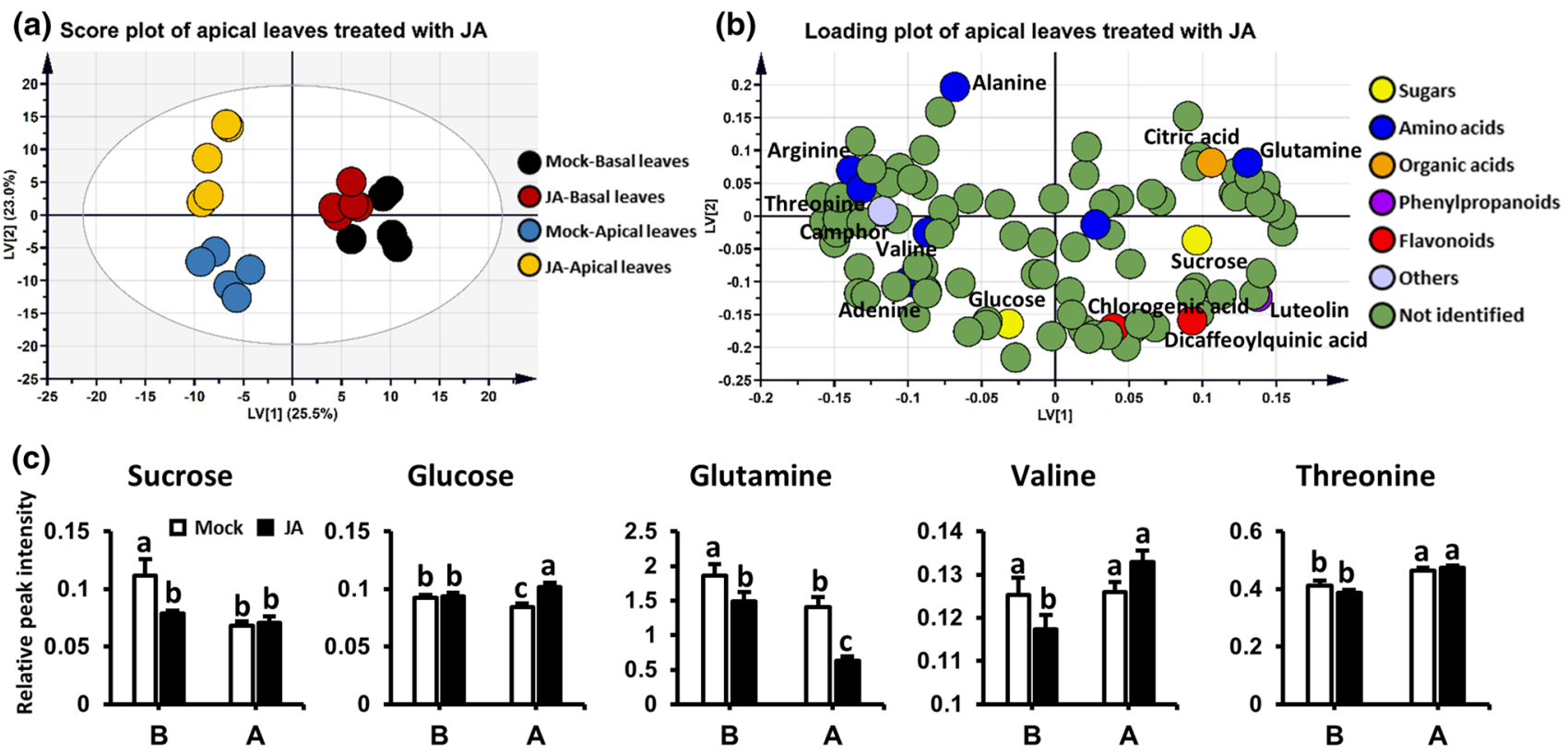

Glucose

Glutamine

Valine

Threonine
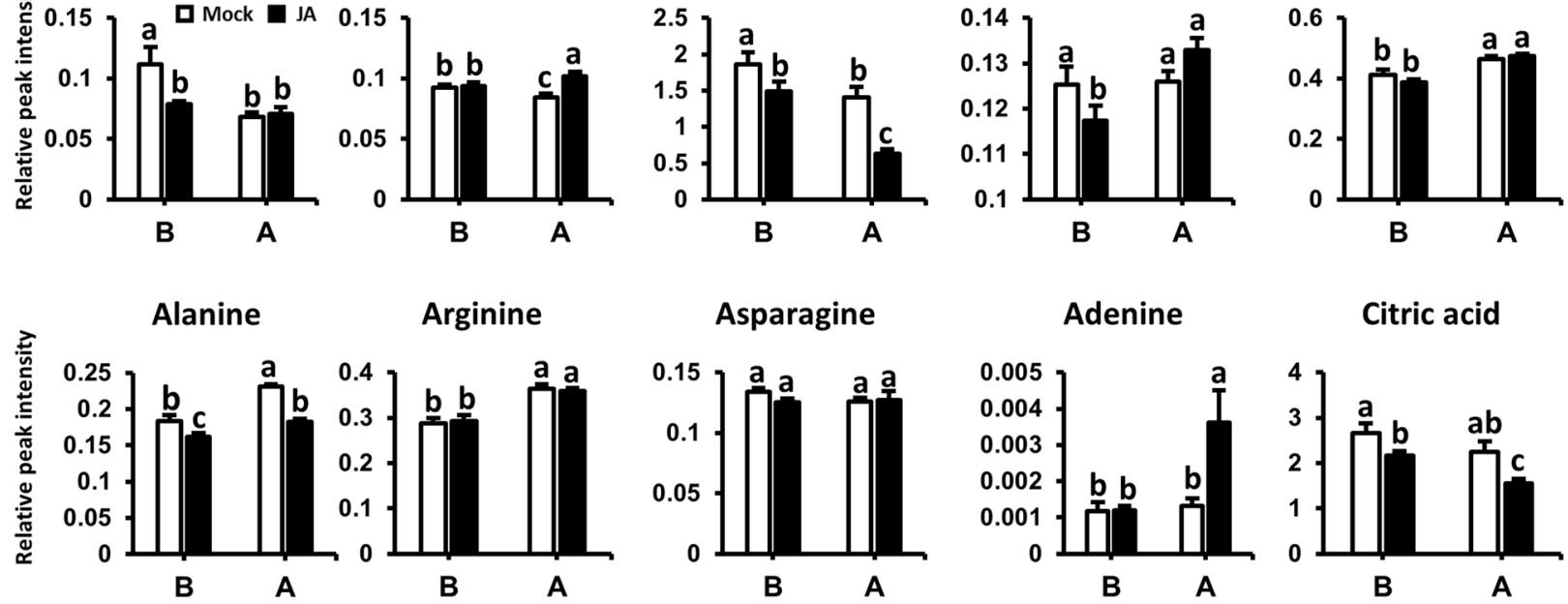

Asparagine

Adenine

Citric acid
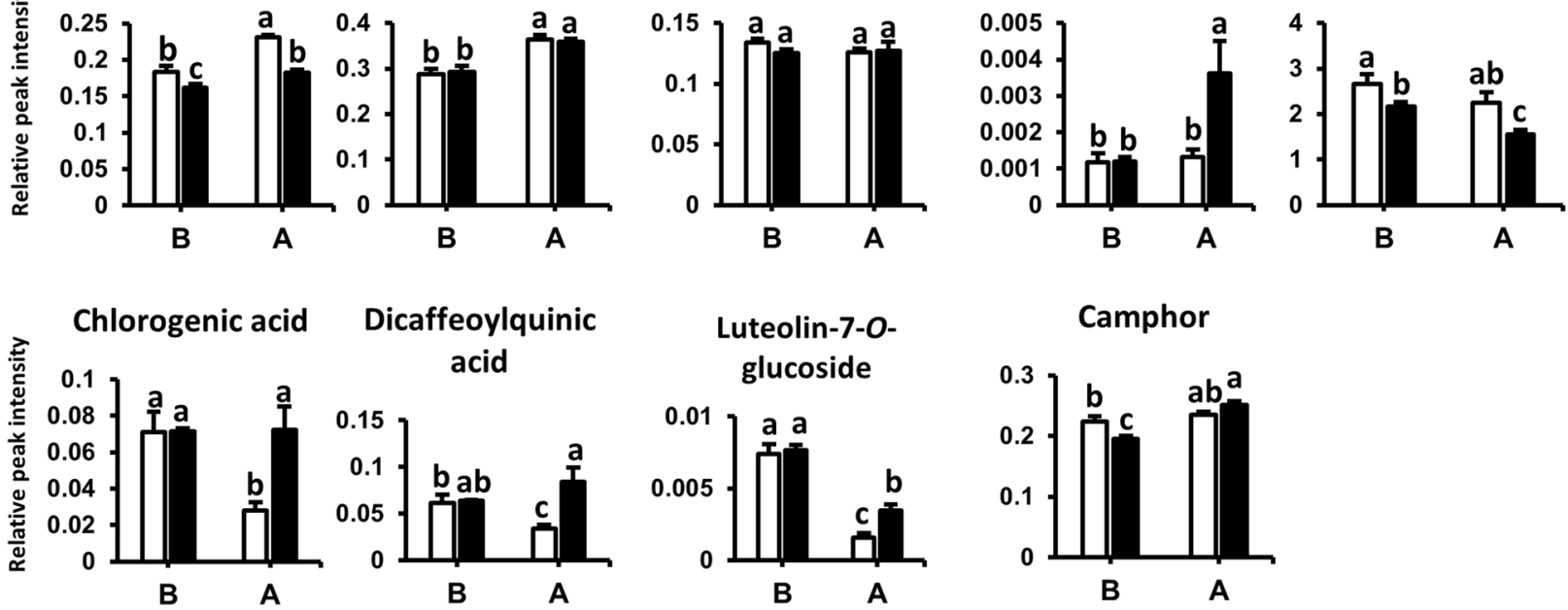

Fig. 6 Metabolomic responses of basal and apical Chrysanthemum leaves to local application of JA to apical leaves. Leaf metabolites were analyzed by NMR in basal (leaf 4-5) and apical (leaf 9-10) leaves of Chrysanthemum plants at 7 days after the local application of mock or jasmonic acid (JA) solutions to basal leaves (9-10 from the bottom). Partial least square-discriminant analysis (PLS-DA) was performed on the obtained ${ }^{1} \mathrm{H}$ NMR spectra $(n=5)$. a Score plot showing the first two latent variables (LVs). The ellipse represents the
Hotelling T2 with 95\% confidence. b Loading plot showing important chemical shifts that contribute most to the model (variable importance in projection, VIP $>1$ ). The identified compounds are shown in the plot. c Relative peak intensity (mean $\pm \mathrm{SE}, n=5$ ) of the identified compounds in basal (B) or apical (A) leaves of mock- and JA-treated plants are shown. Different letters indicate significant differences among groups compared by Fisher's LSD test at $P \leq 0.05$
In a first attempt to investigate whether basal and apical leaves differ in their responses to exogenous JA, we determined the induction of the JA-associated marker and defense-related enzyme PPO (Thaler et al. 1999, 2002; Redman et al. 2001) along the plant canopy. Application of JA to all the plant leaves increased PPO levels in basal and apical leaves (5-9) (Fig. 3a), suggesting that both groups of leaves are responsive to the hormone treatment. However, no systemic induction was observed when only basal or apical leaves were treated with JA (Fig. 3b, c). This is in strong contrast with previous studies in tomato, where the activity of this defense-related protein has been reported to be induced in systemic leaves after local wounding, JA application or herbivory (Stout et al. 1994, 1996). Our results also showed that constitutive PPO activity levels in apical leaves (13-14) were higher than in basal leaves (5-9). Augmented 
PPO activity levels have been reported to confer enhanced plant resistance to arthropod herbivores (Wang and Constabel 2004; Mahanil et al. 2008). PPO catalyzes the oxidation of phenolics to quinones which can chemically interact with plant amino acids or proteins thus decreasing the nutritional quality of leaf tissues for herbivores (Felton and Duffey 1991; Stout et al. 1994). As young apical Chrysanthemum leaves are more susceptible to thrips, our results suggest that differences in constitutive and inducible levels of PPO within the plant canopy might not explain the degree of susceptibility to thrips.

Despite the lack of systemic induction of PPO after local application of JA, we did observe an increased resistance to thrips in systemic leaves of locally induced plants (Fig. 2c, d). Thus, we performed a non-targeted metabolomic NMR analysis to further investigate whether JA affected other leaf chemical defenses against western flower thrips. Our results showed that when JA was applied to all the leaves of Chrysanthemum plants, the metabolomic responses of basal (4-5) leaves were stronger than those of apical (9-10) ones (Fig. 4). Overall, JA increased the concentrations of sugars, phenylpropanoids, flavonoids and some amino acids, and reduced the levels of the amino acid glutamine and the organic acid citric acid in both basal and apical leaves. Yet, these differences were slightly larger in basal leaves. Furthermore, some of the identified compounds, such as sucrose, asparagine, threonine, luteolin and camphor were induced in basal leaves only. Induction of phenolic acids (caffeoylquinic and chlorogenic acid) and the flavonoid luteolin by the volatile form of JA, methyl jasmonate (MeJA), has been previously reported in wild tobacco (N. attenuata), carrot (Daucus carota) and rice (Oryza sativa) (Keinänen et al. 2001; Kong et al. 2004; Heredia and Cisneros-Zevallos 2009). Also, MeJA application has been reported to reduce the concentration of the amino acid glutamine in Arabidopsis (Hendrawati et al. 2006). Enhanced levels of phenolics compounds might have contributed to the higher levels of thrips resistance after JA application in basal and apical leaves. Both chlorogenic acid and caffeoylquinic acid have been reported to contribute to Chrysanthemum resistance to thrips (Leiss et al. 2009b), and higher leaf concentrations of the flavonoid luteolin have been positively associated to thrips resistance in carrot (D. carota L.) (Leiss et al. 2013). In addition, a higher content of sugars might have increased constitutive and hormone-mediated induced defenses. Sugars, including glucose, fructose and sucrose, are reported to be involved in plant development and defenses (Sheen et al. 1999; Smeekens et al. 2010; Trouvelot et al. 2014). They can act as signaling molecules and/or provide resources for the constitutive and inducible production of C-based compounds, such as phenolics (Arnold et al. 2004; Guo et al. 2013). Finally, the reduction in amino acids, such as glutamine, which is a predominant amino acid constituent of the insect gut (Yoshinaga et al. 2003), might have reduced the nutritional value of Chrysanthemum leaves. In summary, JA-mediated induction of chemical defenses (i.e., phenolics and sugars) and reduction in the nitrogen content of the hormone-treated leaves might have contributed to the observed enhanced resistance to thrips (Fig. 2a, b). Interestingly, our results also showed that constitutive chemical defenses of basal and apical leaves significantly differed. Basal (4-5) leaves of mock-treated plants contained slightly higher levels of phenolics (i.e., chlorogenic acid, dicaffeoylquinic acid and flavonoid luteolin-7-O-glucoside), organic acids and sugars (sucrose and glucose), while levels of amino acids were overall reduced when compared to apical (9-10) leaves (Figs. 4c, 5c and 6c). Reduced concentrations of some primary metabolites (i.e., amino acids) and enhanced levels of phenolic compounds might additionally explain why basal leaves were less preferred by thrips independent of the hormone treatment (Fig. 2b, d, f).

Finally, our results also showed that local application of JA to basal leaves barely affected the metabolomic profiles of systemic apical leaves (Fig. 5), and vice versa (Fig. 6), at 7 days after the hormone application. This probably explains why the local induction of basal leaves (4-5) did not alter thrips susceptibility in apical leaves (9-10) (Fig. 2d). Systemic defense responses are often found to be highly variable in space and time, and many studies have reported differences in local and systemic defense responses to herbivory or exogenous hormone application (Babst et al. 2009; Moreira et al. 2009; Lee et al. 2017; Kundu et al. 2018). Systemically induced resistance can be achieved by the systemic transport, through the plant vascular system, of defensive metabolites and/or signals from the induced tissues that activate de novo expression of resistance-associated traits (Heil and Ton 2008). Distribution of defenses within plants is then often controlled by their vascular architecture, and the translocation of leaf compounds occurs mainly among leaves that are in an approximate vertical row (orthostichy) in many plant species (Orians 2005). For instance, in Eastern Cottonwood (Populus deltoides) (Jones et al. 1993), tobacco (Nicotiana attenuata) (Schittko and Baldwin 2003), tomato (S. lycopersicum) (Rhodes et al. 1999), cotton (Gossypium sp.) (Eisenring et al. 2017) and Arabidopsis (A. thaliana) (Ferrieri et al. 2015) leaves with direct vascular connections to the damaged leaf are reported to display stronger chemical defense inductions than leaves without these vascular connections. Our results showed that local application of JA to both basal or apical leaves increased plant resistance to thrips in leaves developed after the induction treatment (13-18) (Fig. 2c, d), albeit at different magnitudes. This suggests that they might share direct vascular connections. Alternatively, a stronger sink strength in these new developed leaves (13-18) might have attenuated the systemic 
responses in mature leaves (9-10). For instance, Arnold and Schultz (2002) showed that JA treatment enhanced sink strength in the developing leaves of hybrid poplar saplings, which resulted in a higher import of carbohydrates and production of condensed tannins in those leaves. Additional analyses are needed to explore if the induced systemic resistance to thrips in leaves 13-18 correlates with increases in imported resources and chemical defenses from the adjacent leaves (9-10).

In conclusion, we showed that local and systemic JAmediated induction of chemical defenses in Chrysanthemum is spatially variable and dependent on the site of the induction. Furthermore, we showed that higher levels of constitutive and inducible defenses in basal leaves might explain the distribution of thrips-associated feeding within the Chrysanthemum plant canopy. Yet our data also demonstrate that apical leaves, which were preferred by thrips, induced a stronger systemic protection against thrips in leaves that were developed after the hormone induction, contributing most to the enhanced resistance to this insect. Our study has important implications for agriculture, as the use of elicitors to enhance host-plant resistance to pest and pathogens represents an alternative strategy to the use of pesticides (Steenbergen et al. 2018). Yet the variations in within-plant induction of chemical defenses described here highlight that the mode of application of these elicitors is highly relevant to induce systemic protection in Chrysanthemum.

Author contribution statement GC, PK and RE-B designed the experiment. GC conducted the experiments. GC, PK and RE-B performed the data analysis and interpretation. GC and $\mathrm{HK}$ interpreted the NMR data. GC wrote the draft of the manuscript. All authors critically reviewed and approved the final version of the manuscript.

Acknowledgements This work was supported by the Technology Foundation STW, project 'Green Defense against Pests' (GAP) (Ref.13,553); we thank the companies involved in the GAP project: Rijk Zwaan, Dümmen Orange, Dekker Chrysanten, Deliflor Chrysanten and Incotec for their financial support. Gang Chen is funded by the China Scholarship Council (CSC) of the Ministry of Education.

\section{Compliance with ethical standards}

Conflict of interest The authors declare no conflict of interests.

Ethical standard There is no ethical standard related to the present article.

Open Access This article is distributed under the terms of the Creative Commons Attribution 4.0 International License (http://creativeco mmons.org/licenses/by/4.0/), which permits unrestricted use, distribution, and reproduction in any medium, provided you give appropriate credit to the original author(s) and the source, provide a link to the Creative Commons license, and indicate if changes were made.

\section{References}

Abe H, Ohnishi J, Narusaka M, Seo S, Narusaka Y, Tsuda S, Kobayashi M (2008) Function of jasmonate in response and tolerance of Arabidopsis to thrip feeding. Plant Cell Physiol 49(1):68-80

Abe H, Shimoda T, Ohnishi J, Kugimiya S, Narusaka M, Seo S, Narusaka Y, Tsuda S, Kobayashi M (2009) Jasmonate-dependent plant defense restricts thrips performance and preference. BMC Plant Biol 9(1):97

Abe H, Tomitaka Y, Shimoda T, Seo S, Sakurai T, Kugimiya S, Tsuda S, Kobayashi M (2011) Antagonistic plant defense system regulated by phytohormones assists interactions among vector insect, thrips and a tospovirus. Plant Cell Physiol 53(1):204-212

Agrawal AA (2007) Macroevolution of plant defense strategies. Trends Ecol Evol 22(2):103-109

Agrawal AA, Karban R (1999) Why induced defenses may be favored over constitutive strategies in plants. In: Tollrian R, Harvell CD (eds) The ecology and evolution of inducible defenses. Princeton University Press, Princeton, pp 45-61

Arimura G, Huber DPW, Bohlmann J (2004) Forest tent caterpillars (Malacosoma disstria) induce local and systemic diurnal emissions of terpenoid volatiles in hybrid poplar (Populus trichocarpa $\times$ deltoides): cDNA cloning, functional characterization, and patterns of gene expression of (-)-germacrene D synthase, PtdTPS1. Plant J 37(4):603-616

Arnold TM, Schultz JC (2002) Induced sink strength as a prerequisite for induced tannin biosynthesis in developing leaves of Populus. Oecologia 130(4):585-593

Arnold T, Appel H, Patel V, Stocum E, Kavalier A, Schultz J (2004) Carbohydrate translocation determines the phenolic content of Populus foliage: a test of the sink-source model of plant defense. New Phytol 164(1):157-164

Babst BA, Sjödin A, Jansson S, Orians CM (2009) Local and systemic transcriptome responses to herbivory and jasmonic acid in Populus. Tree Genet Genomes 5(3):459-474

Bari R, Jones JDG (2009) Role of plant hormones in plant defence responses. Plant Mol Biol 69(4):473-488

Bosch M, Berger S, Schaller A, Stintzi A (2014) Jasmonate-dependent induction of polyphenol oxidase activity in tomato foliage is important for defense against Spodoptera exigua but not against Manduca sexta. BMC Plant Biol 14(1):257

Chen G, Klinkhamer PGL, Escobar-Bravo R, Leiss KA (2018) Type VI glandular trichome density and their derived volatiles are differently induced by jasmonic acid in developing and fully developed tomato leaves: implications for thrips resistance. Plant Sci 276:87-98

Cohen Y, Gisi U, Niderman T (1993) Local and systemic protection against Phytophthora infestans induced in potato and tomato plants by jasmonic acid and jasmonic methyl ester. Phytopathology 83(10):1054-1062

Constabel CP, Barbehenn RV (2008) Defensive roles of polyphenol oxidase in plants. In: Schaller A (ed) Induced plant resistance to herbivory. Springer, New York, pp 253-269

Constabel C, Yip L, Patton YJ, Christopher ME (2000) Polyphenol oxidase from hybrid poplar Cloning and expression in response to wounding and herbivory. Plant Physiol 124(1):285-296

de Jager CM, Butôt RPT, Klinkhamer PGL, Van Der Meijden E (1995a) Chemical characteristics of chrysanthemum cause resistance to Frankliniella occidentalis (Thysanoptera: Thripidae). J Econ Entomol 88(6):1746-1753 
de Jager KM, Butôt RPT, Guldemond A (1995b) Genetic variation in chrysanthemum for resistance to western flower thrips and Thrips tabaci. In: Parker BL, Skinner M, Lewis T (eds) Thrips biology and management. NATO ASI Series (Series A: Life Sciences). Springer, Boston, pp 403-406

De Vos M, Van Oosten VR, Van Poecke RM, Van Pelt JA, Pozo MJ, Mueller MJ, Buchala AJ, Métraux J-P, Van Loon L, Dicke M, Corné MJP (2005) Signal signature and transcriptome changes of Arabidopsis during pathogen and insect attack. Mol Plant Microbe Interact 18(9):923-937

Eisenring M, Meissle M, Hagenbucher S, Naranjo SE, Wettstein F, Romeis J (2017) Cotton defense induction patterns under spatially, temporally and quantitatively varying herbivory levels. Front Plant Sci 8:234

Escobar-Bravo R, Klinkhamer PGL, Leiss KA (2017) Induction of jasmonic acid-associated defenses by thrips alters host suitability for conspecifics and correlates with increased trichome densities in tomato. Plant Cell Physiol 58(3):622-634

Felton GW, Duffey SS (1991) Reassessment of the role of gut alkalinity and detergency in insect herbivory. J Chem Ecol 17(9):1821-1836

Ferrieri AP, Appel HM, Schultz JC (2015) Plant vascular architecture determines the pattern of herbivore-induced systemic responses in Arabidopsis thaliana. PLoS One 10(4):e0123899

Glazebrook J (2005) Contrasting mechanisms of defense against biotrophic and necrotrophic pathogens. Annu Rev Phytopathol 43:205-227

Guo R, Shen W, Qian H, Zhang M, Liu L, Wang Q (2013) Jasmonic acid and glucose synergistically modulate the accumulation of glucosinolates in Arabidopsis thaliana. J Exp Bot 64(18):5707-5719

Heil M, Ton J (2008) Long-distance signalling in plant defence. Trends Plant Sci 13(6):264-272

Hendrawati O, Yao Q, Kim HK, Linthorst HJM, Erkelens C, Lefeber AWM, Choi YH, Verpoorte R (2006) Metabolic differentiation of Arabidopsis treated with methyl jasmonate using nuclear magnetic resonance spectroscopy. Plant Sci 170(6):1118-1124

Heredia JB, Cisneros-Zevallos L (2009) The effect of exogenous ethylene and methyl jasmonate on pal activity, phenolic profiles and antioxidant capacity of carrots (Daucus carota) under different wounding intensities. Postharvest Biol Technol 51(2):242-249

Hilleary R, Gilroy S (2018) Systemic signaling in response to wounding and pathogens. Curr Opin Plant Biol 43:57-62

Howe GA, Jander G (2008) Plant immunity to insect herbivores. Annu Rev Plant Biol 59:41-66

Jones CG, Hopper RF, Coleman JS, Krischik VA (1993) Control of systemically induced herbivore resistance by plant vascular architecture. Oecologia 93(3):452-456

Keinänen M, Oldham NJ, Baldwin IT (2001) Rapid HPLC screening of jasmonate-induced increases in tobacco alkaloids, phenolics, and diterpene glycosides in Nicotiana attenuata. J Agric Food Chem 49(8):3553-3558

Kim HK, Choi YH, Verpoorte R (2011) NMR-based plant metabolomics: where do we stand, where do we go? Trends Biotechnol 29(6):267-275

Köhler A, Maag D, Veyrat N, Glauser G, Wolfender J-L, Turlings TCJ, Erb M (2015) Within-plant distribution of 1, 4-benzoxazin-3-ones contributes to herbivore niche differentiation in maize. Plant Cell Environ 38(6): 1081-1093

Kong C, Hu F, Zhang C, Xu X (2004) Inducible effects of methyl jasmonate on allelochemicals from rice. Acta Ecol Sin 24(2):177-180

Kundu A, Mishra S, Vadassery J (2018) Spodoptera litura-mediated chemical defense is differentially modulated in older and younger systemic leaves of Solanum lycopersicum. Planta 248(4):981-997
Lazebnik J, Frago E, Dicke M, van Loon JJA (2014) Phytohormone mediation of interactions between herbivores and plant pathogens. J Chem Ecol 40(7):730-741

Lee G, Joo Y, Kim SG, Baldwin IT (2017) What happens in the pith stays in the pith: tissue-localized defense responses facilitate chemical niche differentiation between two spatially separated herbivores. Plant J 92(3):414-425

Leiss KA, Choi YH, Abdel-Farid IB, Verpoorte R, Klinkhamer PGL (2009a) NMR metabolomics of thrips (Frankliniella occidentalis) resistance in Senecio hybrids. J Chem Ecol 35(2):219-229

Leiss KA, Maltese F, Choi YH, Verpoorte R, Klinkhamer PGL (2009b) Identification of chlorogenic acid as a resistance factor for thrips in chrysanthemum. Plant Physiol 150(3):1567-1575

Leiss KA, Cristofori G, van Steenis R, Verpoorte R, Klinkhamer PGL (2013) An eco-metabolomic study of host plant resistance to Western flower thrips in cultivated, biofortified and wild carrots. Phytochemistry 93:63-70

Li C, Williams MM, Loh YT, Lee GI, Howe GA (2002) Resistance of cultivated tomato to cell content-feeding herbivores is regulated by the octadecanoid-signaling pathway. Plant Physiol 130(1):494-503

López-Gresa MP, Lisón P, Kim HK, Choi YH, Verpoorte R, Rodrigo I, Conejero V, Bellés JM (2012) Metabolic fingerprinting of tomato mosaic virus infected Solanum lycopersicum. J Plant Physiol 169(16): 1586-1596

Mahanil S, Attajarusit J, Stout MJ, Thipyapong P (2008) Overexpression of tomato polyphenol oxidase increases resistance to common cutworm. Plant Sci 174(4):456-466

Moreira X, Sampedro L, Zas R (2009) Defensive responses of Pinus pinaster seedlings to exogenous application of methyl jasmonate: concentration effect and systemic response. Environ Exper Bot 67(1):94-100

Obata T, Fernie AR (2012) The use of metabolomics to dissect plant responses to abiotic stresses. Cell Mol Life Sci 69(19):3225-3243

Ohnmeiss TE, Baldwin IT (2000) Optimal defense theory predicts the ontogeny of an induced nicotine defense. Ecology 81(7): $1765-1783$

Orians C (2005) Herbivores, vascular pathways, and systemic induction: facts and artifacts. J Chem Ecol 31(10):2231-2242

Pieterse CMJ, Zamioudis C, Berendsen RL, Weller DM, Van Wees SCM, Bakker PAHM (2014) Induced systemic resistance by beneficial microbes. Annu Rev Phytopathol 52:347-375

Redman AM, Cipollini DF Jr, Schultz JC (2001) Fitness costs of jasmonic acid-induced defense in tomato, Lycopersicon esculentum. Oecologia 126(3):380-385

Rhodes JD, Thain JF, Wildon DC (1999) Evidence for physically distinct systemic signalling pathways in the wounded tomato plant. Ann Bot 84(1):109-116

Schittko U, Baldwin IT (2003) Constraints to herbivore-induced systemic responses: bidirectional signaling along orthostichies in Nicotiana attenuata. J Chem Ecol 29(3):763-770

Sheen J, Zhou L, Jang JC (1999) Sugars as signaling molecules. Curr Opin Plant Biol 2(5):410-418

Smeekens S, Ma J, Hanson J, Rolland F (2010) Sugar signals and molecular networks controlling plant growth. Curr Opin Plant Biol 13(3):273-278

Smith JL, De Moraes CM, Mescher MC (2009) Jasmonate-and salicylate- mediated plant defense responses to insect herbivores, pathogens and parasitic plants. Pest Manag Sci 65(5):497-503

Steenbergen M, Abd-el-Haliem A, Bleeker P, Dicke M, Escobar-Bravo R, Cheng G, Haring MA, Kant MR, Kappers I, Klinkhamer PGL, Leiss KA, Legarrea S, Macel M, Mouden S, Pieterse CMJ, Sarde SJ, Schuurink RC, De Vos M, Van Wees SCM, Broekgaarden C (2018) Thrips advisor: exploiting thrips-induced defences to combat pests on crops. J Exp Bot 69(8):1837-1848 
Stout MJ, Workman J, Duffey SS (1994) Differential induction of tomato foliar proteins by arthropod herbivores. J Chem Ecol 20(10):2575-2594

Stout MJ, Workman KV, Duffey SS (1996) Identity, spatial distribution, and variability of induced chemical responses in tomato plants. Entomol Exp Appl 79(3):255-271

Stout MJ, Workman KV, Bostock RM, Duffey SS (1998) Stimulation and attenuation of induced resistance by elicitors and inhibitors of chemical induction in tomato (Lycopersicon esculentum) foliage. Entomol Exp Appl 86(3):267-279

Thaler JS, Fidantsef AL, Duffey SS, Bostock RM (1999) Trade-offs in plant defense against pathogens and herbivores: a field demonstration of chemical elicitors of induced resistance. J Chem Ecol 25(7):1597-1609

Thaler JS, Karban R, Ullman DE, Boege K, Bostock RM (2002) Crosstalk between jasmonate and salicylate plant defense pathways: effects on several plant parasites. Oecologia 131(2):227-235

Trouvelot S, Héloir MC, Poinssot B, Gauthier A, Paris F, Guillier C, Combier M, Trdá L, Daire X, Adrian M (2014) Carbohydrates in plant immunity and plant protection: roles and potential application as foliar sprays. Front Plant Sci 5:592

Tsunoda T, Grosser K, van Dam NM (2018) Locally and systemically induced glucosinolates follow optimal defence allocation theory upon root herbivory. Funct Ecol 32(9):2127-2137
Van Dam NM, Horn M, Mareš M, Baldwin IT (2001) Ontogeny constrains systemic protease inhibitor response in Nicotiana attenuata. J Chem Ecol 27(3):547-568

van Geest G, Choi YH, Arens P, Post A, Liu Y, van Meeteren U (2016) Genotypic differences in metabolomic changes during storage induced-degreening of chrysanthemum disk florets. Postharvest Biol Technol 115:48-59

Walling LL (2000) The myriad plant responses to herbivores. J Plant Growth Regul 19(2):195-216

Wang J, Constabel CP (2004) Polyphenol oxidase overexpression in transgenic Populus enhances resistance to herbivory by forest tent caterpillar (Malacosoma disstria). Planta 220(1):87-96

Yoshinaga N, Sawada Y, Nishida R, Kuwahara Y, Mori N (2003) Specific incorporation of L-glutamine into volicitin in the regurgitant of Spodoptera litura. Biosci Biotechnol Biochem 67(12):2655-2657

Publisher's Note Springer Nature remains neutral with regard to jurisdictional claims in published maps and institutional affiliations. 